\title{
MANAGING BRIDGE SCOUR RISK USING STRUCTURAL HEALTH MONITORING
}

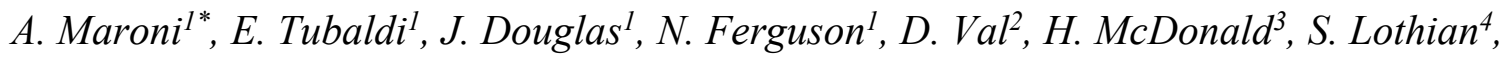 \\ A. Chisholm ${ }^{5}$, O. Riches ${ }^{5}$, D. Walker ${ }^{3}$, E. Greenoak ${ }^{4}$, C. Green ${ }^{4}$ and D. Zonta ${ }^{1}$ \\ ${ }^{I}$ Department of Civil and Environmental Engineering, University of Strathclyde, Glasgow, United Kingdom \\ ${ }^{2}$ School of Energy, Geoscience, Infrastructure and Society, Heriot-Watt University, Edinburgh, United Kingdom; \\ ${ }^{3}$ Trunk Road and Bus Operations, Transport Scotland, Glasgow, United Kingdom \\ ${ }^{4}$ Network Rail Scotland Route, Glasgow, United Kingdom \\ ${ }^{5}$ ARUP Scotland, Edinburgh, United Kingdom \\ * Corresponding author
}

\begin{abstract}
Scour is the leading cause of bridge failures worldwide. In the United States, 22 bridges fail every year, whereas in the UK scour contributed significantly to the 138 bridge collapses recorded in the last century. In Scotland, there are around 2,000 bridges susceptible to scour. Scour assessments are currently based on visual inspections, which are expensive, time-consuming, and the information collected is qualitative. However, monitoring an entire infrastructure network against scour is not economically feasible. A way to overcome this limitation is to install monitoring systems at critical locations, and then extend the pieces of information gained to the entire asset through a probabilistic approach. This paper proposes a Decision Support System (DSS) for bridge scour management that exploits information from a limited number of scour monitoring systems to achieve a more confined estimate of the scour risk for a bridge network. A Bayesian network (BN) is used to describe conditional dependencies among the involved random variables. The BN allows estimating, and updating, the scour depth distributions using information from monitoring of scour depth and river flow characteristics. Data collected by the monitoring system and BN's outcomes are then used to inform a decision model and thus support transport agencies' decision frameworks. A case study consisting of several road bridges in Scotland is considered to demonstrate the functioning of the DSS. The BN is found to estimate accurately the scour depth at unmonitored bridges, and the decision model provides higher values of scour thresholds compared to the ones implicitly chosen by the transport agencies.
\end{abstract}

\section{Introduction and background}

Bridge scour is the excavation of material around underwater foundations due to the erosive action of the stream (Kirby et al., 2015). The total scour at a bridge site results from the combination of different types of scour, namely general, constriction and local scour (Figure 1). While the first type is associated with the natural evolution of the river bed, the other two are attributable to the interaction between the bridge and the flow. Constriction scour is the result of confining the river channel width between bridge abutments and piers, while local scour is caused by the interference of individual structural elements with the flow. Scour processes occur naturally and are expected to occur at most bridges during their service life (Kirby et al., 2015), since every structure founded on river bed is prone to scour around its foundations. When the scour depth becomes significant, the foundation and bridge stability may be compromised, leading to structural instability and failure. Scour is the principal cause of failure of bridges worldwide, resulting in significant deaths, traffic disruptions and economic losses (Wardhana and Hadipriono, 2003).

In the UK, there are around 9,000 bridges over waterways and 95,000 bridge spans are susceptible to scour processes. According to van Leeuwen and Lamb (2014), scour was identified as the most common cause of 138 bridge failures in
1846-2013. Reviews of 1,502 river crossing failures occurred in the USA in the period 1966-2005 revealed that scour was the cause of $58 \%$ of the recorded failures (Briaud et al., 2007).

Network Rail owns 19,000 bridges nationally: 8,700 structures are held in a National Scour Database. In Scotland, 1,750 railway bridges are inspected for scour, and 58 are at high risk. Transport Scotland is responsible for the Scottish road network including 1,567 bridges over water. Around $8 \%$ are classified as needing scour monitoring and protection measures.

Figure 1 Types of scour (Kirby et al., 2015)

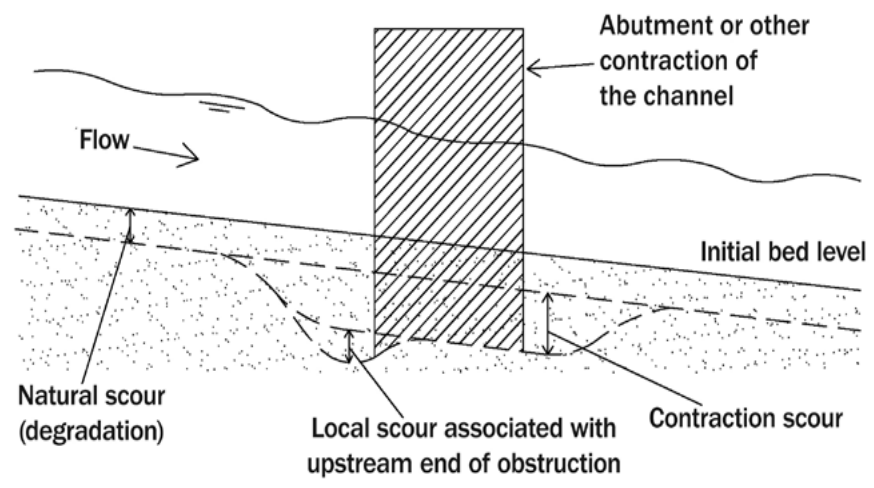




\subsection{Scour risk assessment and decision process}

First examples of structural risk assessment frameworks have been developed in the context of seismic engineering (Porter, 2003), but in the recent years, probabilistic frameworks have been proposed for flood and coastal engineering (FEMA, 2005).

The assessment of the scour risk is an important component of any bridge scour management system. This assessment should combine information on the scour hazard, the bridge vulnerability, and the consequences of failure. It should involve a probabilistic approach due to the many uncertainties inherent to the future flood occurrence and intensity, the bridge state, and capability to withstand the effects of the scour action (Roca and Whitehouse, 2012; Tubaldi et al., 2017). Structural health monitoring (SHM) can be very helpful in supporting decision-makers involved in bridge management. SHM and decision-making are two separate processes, occurring one downstream of the other (Cappello et al., 2016). Monitoring is about acquiring information on the bridge state while decisionmaking is about choosing the best action to undertake based on the structural state assessed via SHM and the estimated risk (Bolognani et al., 2017).

The current practice for bridge scour inspection depends on visual checks carried out, in normal conditions, every two years. Transport Scotland and Network Rail assess the scour risk using the Procedures BD 97/12 (Department of Transport, 2012) and EX2502 (HR Wallingford, 1993), respectively. The decision frameworks followed by Transport Scotland and Network Rail are defined by their own plan, the "Scour Management Strategy and Flood Emergency Plan" (Transport Scotland, 2018) and the "Scotland Adverse and Extreme Weather Plan" (Network Rail, 2016). They provide a framework for the management of bridges after an extreme weather event.

In this paper, the prototype of a Decision Support System (DSS) for bridge scour management is presented; it consists of a scour hazard model and a decision model. The former model is based on a Bayesian Network (BN), which is a probabilistic graphical model describing a set of random variables and their conditional dependencies via a directed acyclic graph (Jensen and Nielsen, 2007). The BN can estimate, and update, the scour depth in the surrounding of bridge foundations using information from a monitoring system and river flow characteristics. The latter model can update the scour threshold after which bridges are closed by exploiting BN's outcomes and observations collected by a scour monitoring system.
Section 2 illustrates the BN for scour estimation and the decision model. Section 3 presents the network built to demonstrate the functioning of the BN. Three bridges located over the same river are considered, with only one instrumented with a scour monitoring system. Section 4 reports some results obtained by applying the proposed framework.

\section{Methodology}

Monitoring any location of a bridge stock against scour is not economically feasible. One way to overcome this issue is to install scour monitoring systems only at critical bridge locations (i.e., bridges that have experienced in the past significant scour) and then using a probabilistic approach to extend the information to the entire asset. A Bayesian network (BN) can be used for this purpose. Figure 2 shows the schematic rationale of this approach. The pilot scour monitoring system measures the scour depth at a pier of one bridge; the Bayesian network then extent the piece of information to all the unmonitored bridges, thus estimating and updating the depth of scour holes at their piers.

A BN represents the causal probabilistic relationship among a set of random variables, their conditional dependences, and it provides a compact representation of a joint probability distribution (Rehg, et al., 1999). The presence of a link between two nodes means that the node that appears earlier in the chain has a direct influence upon the other connected node. In BN terminology, a node is a parent of a child if there is a link from the former to the latter. Probabilistic inference in BNs takes two forms: predictive analysis that is based on evidence on parent nodes and Bayesian learning where observations enter into the BN through child nodes (Ben Gal, 2007). The pdf of child nodes can be estimated and updated by carrying out the former analysis, whereas the latter one allows updating the pdf of parent nodes.

In recent years, there has been an increasing amount of literature on the use of Bayesian Networks proving that BN framework is a growingly popular approach to represent probabilistic models. BNs are based on technologies developed mainly within the artificial intelligence community (Korb and Nicholson, 2010), but they have become quickly popular in every field of studies thanks to their excellent performance and suitability on dealing with a wide range of problems involving uncertainty and probabilistic reasoning. Their increasing availability in inexpensive software systems has also helped to spread their use in risk management.

Figure 2: Schematic rationale of the scour hazard model

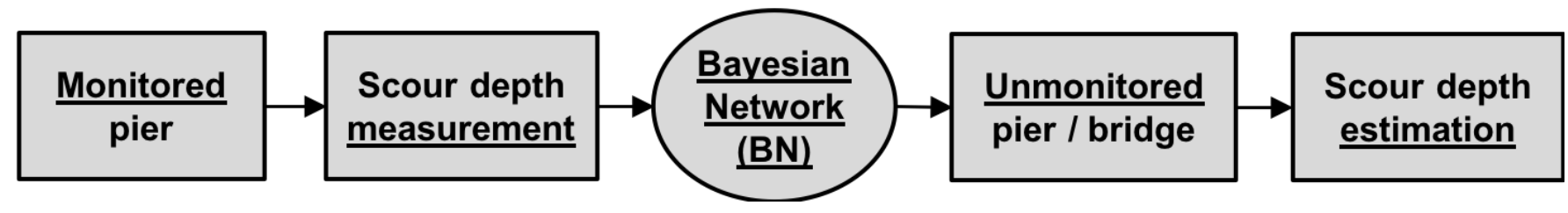


Bayesian networks started to be used for Bayesian modelling in engineering risk analysis due to their ability to deal with uncertainties in complex systems (Faber et al., 2002; FriisHansen, 2000; Straub, 2009). Past applications to bridge assets addressed particularly seismic risk (Bensi et al., 2011).

Bayesian network relies on a single tool, Bayes' theorem shown in Equation (1):

$$
p d f(\theta \mid \mathbf{y})=\frac{p d f(\theta) \times p d f(\mathbf{y} \mid \theta)}{p d f(\mathbf{y})}
$$

where $p d f(\theta \mid \boldsymbol{y})$ is the posterior probability distribution function (pdf) of the parameter $\theta$ given the observed data $\boldsymbol{y}$. The probability $p d f(\boldsymbol{y} \mid \theta)$ is known as the likelihood of the observed data $y$ given the parameter $\theta$ and it is multiplied by $p d f(\theta)$, the prior pdf of parameter $\theta$. This latter pdf expresses one's beliefs about an uncertain quantity before some evidence is taken into account. The probability at the denominator, $p d f(\boldsymbol{y})$, is called evidence and represents a normalizing factor to make the posterior pdf sum to 1 . Bayes' rule describes how the probability of parameter $\theta$ changes given information gained from measured data $y$.

\subsection{Scour hazard model}

The BN employed in the scour hazard model is developed according to the BD 97/12 (Department of Transport, 2012). Starting from the river flow characteristics, the total scour depth $D_{T}$ (Figure 3 ) is estimated by summing the effects of constriction scour $\left(D_{C}\right)$ and local scour $\left(D_{L}\right)$. Model uncertainties are added to reproduce the randomness of the estimation processes.

Manning equation is used to describe the relationship between river flow $Q$ and upstream river level $y_{U}$. Two model uncertainties are employed: $e_{M}$ is the correlated error of the Manning equation and ${ }^{(j)} e_{M}$ is the uncorrelated error in the $\mathrm{j}^{\text {th }}$ bridge. $Q, y_{U}$ and the bed material grain size $d$ are then the input of a nonlinear system consisting of 3 equations - the Colebrook-White equation (Equation (2a)) (Kirby et al., 2015), the conservation of fluid mass (Equation (2b)), and the Bernoulli equation (Equation (2c)) - uses to evaluate the average constriction scour $D_{c, \text { ave }}$, the water level through the bridge $y_{B}$, and the threshold velocity $v_{B, c}$. Model errors are added to the C-W equation alone: the correlated, $e_{v B, c}$ and the uncorrelated error, ${ }^{(j)} e_{v B, c}$. The mechanism causing local scour at piers is the formation of vortices at their base, and the pier width $W_{P}$ is the primary controlling parameter. Two model uncertainties are again added: the correlated one, $e_{D L}$ and the uncorrelated one, ${ }^{(j)} e_{D L}$.
Figure $3 \mathrm{BN}$ for scour estimation at a single bridge location

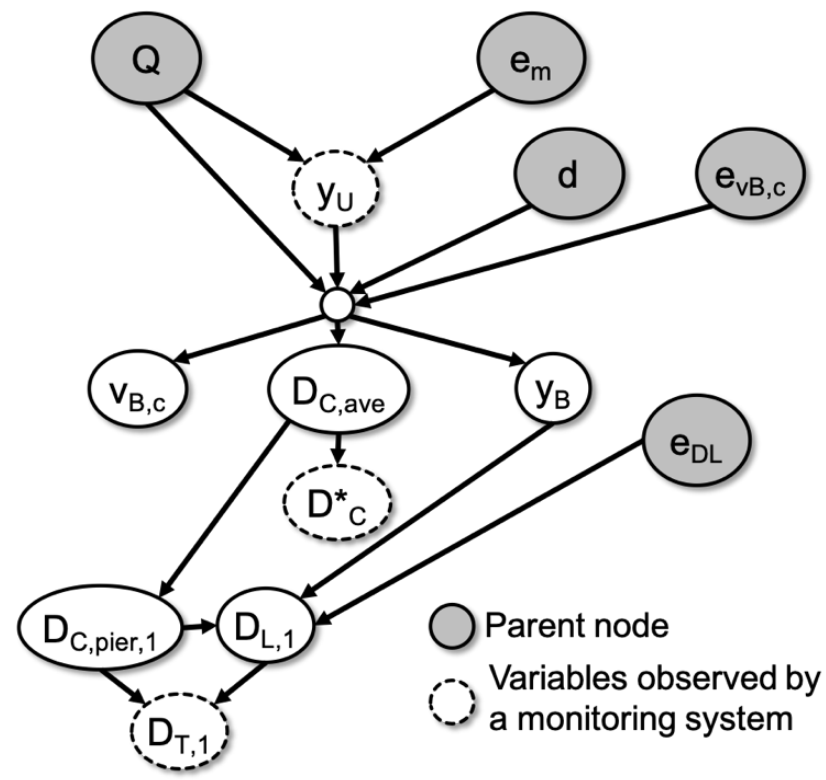

With reference to the presented $\mathrm{BN}$, three quantities are monitored: $y_{U}, D_{T}$ and the constriction scour $D_{C}^{*}$ measured in the middle of the channel. Environmental agencies can provide water level data from gauging stations while SHM sensors to detect scour exist in the market (Prendergast and Gavin, 2014). When new observations become available, the BN model allows propagating information through the network to update probabilities (Jensen and Nielsen, 2007). For this reason, BN can be merged with SHM systems to update the risk map of infrastructure systems.

The BN solution can be broken down into three steps:

- defining the prior pdfs of the parent nodes;

- (ii) splitting the BN into three sub-networks to have three different updating: $y_{U}$ updates $e_{M} ; D^{*}{ }_{C}$ and $y_{U}$ update $e_{v B, c}$ and $d ; D_{T}, y_{U}$ and $D^{*}{ }_{C}$ update $e_{D L}$;

- (iii) updating the descendant nodes.

The $\mathrm{BN}$ can be extended to a second bridge with $\mathrm{N}$ piers because the scour estimation is based on the same models; therefore, the correlated model errors are the same ones. These connections allow the BN to spread information gained from a scour monitoring system to each sub-network (i.e., unmonitored bridge).

$$
\left\{\begin{array}{l}
v_{b, c}-\sqrt{32} v_{0}(d) \cdot \log _{10}\left(\frac{d}{12\left(y_{B}+D_{c, a v e}\right)}+\frac{0.222 v}{\left(y_{B}+D_{c, a v e}\right) \cdot v_{0}(d)}\right)\left(1+e_{v B, c}+{ }^{(j)} e_{v B, c}\right) \\
Q=v_{B, c}\left(y_{B}+D_{c, a v e}\right) B_{B} \\
y_{U}+\frac{\left(Q / y_{U} B_{U}\right)^{2}}{2 \mathrm{~g}}=y_{B}+\frac{v_{B, c}^{2}}{2 \mathrm{~g}}
\end{array}\right.
$$




\subsection{Decision Model}

Transport agencies, such as Transport Scotland or Network Rail, carry out the assessment of the scour risk at highway and railway structures in accordance with the rules defined by codes, procedure or national standard. In particular, these two agencies assess the risks associated with scour and other effects on highway and railway structures during floods using the Procedures BD 97/12 (Department of Transport, 2012) and EX2502 (HR Wallingford, 1993), respectively.

The procedures provide a bridge scour risk classification (Figure 4). The input parameter in Transport Scotland classification (Figure 4(a)) is the relative scour depth $D_{R}$, that is, the ratio between $D_{T}$ and the foundation depth $D_{F}$. Furthermore, a priority factor $P_{F}$ enters into Transport Scotland scour risk rating and it depends on several parameters, such as

Figure 4 Scour risk classification performed by Transport Scotland (a), and Network Rail (b)

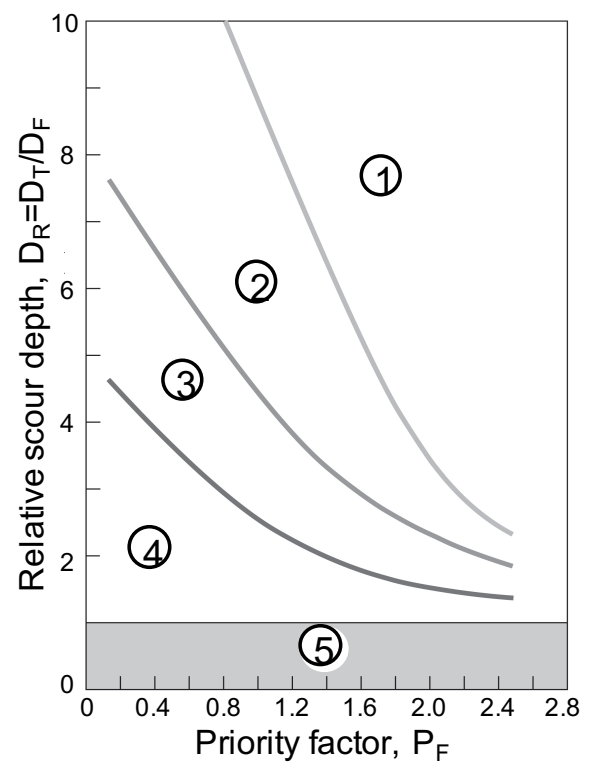

(a)

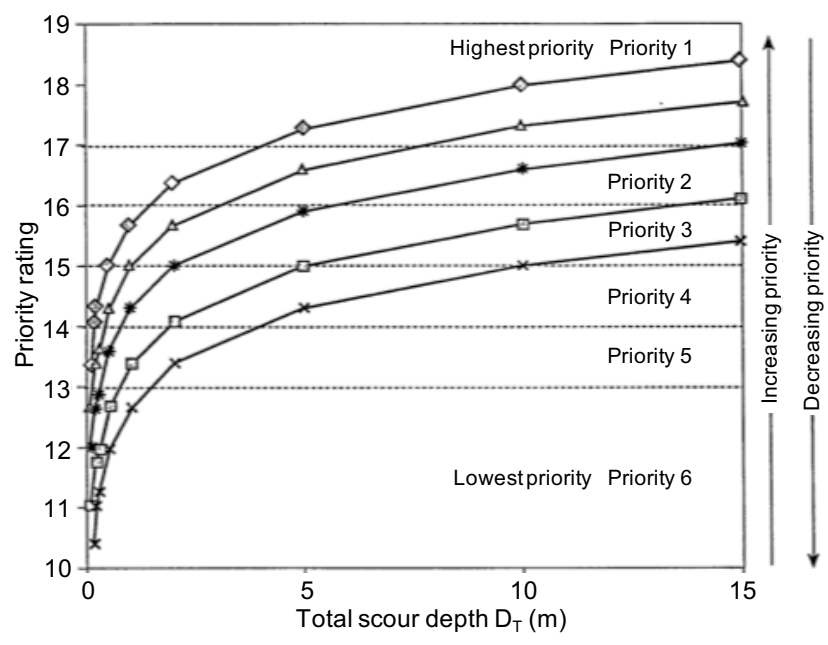

(b) the history of scour problems, the type of foundation and the importance of the bridge (i.e., vehicle traffic volume). The scour risk classification carried out by Network Rail is performed according to the graph depicts in Figure 4(b). It shows different curves according to the foundation depth, consequently, both transport agencies use the relative scour depth $D_{R}$ to categorise bridges at high risk of scour. Transport Scotland classification consists of five classes while Network Rail method has six classes, and bridges with the highest priority fall into class 1 in the two procedures. When a bridge is categorised into category 1 or 2 , it is considered at high scour risk for both agencies.

The actions to be taken by Transport Scotland and Network Rail after a flooding event are defined by their plans (Transport Scotland, 2018; Network Rail, 2016) They provide the triggers that determine what actions needs to take place and a "visual" decision scheme based on water level markers. Transport Scotland defines a red marker in correspondence of the 1 in 200-year flood level whereas Network Rail as the water level associated with a Priority Score $\geq 16$. The transport agencies fix these thresholds by choosing a level of risk they are willing to accept, such that the losses due to the bridge closure equal those due to bridge failure.

The idea behind the proposed decision model is to use the updated scour depth to inform decision about bridge scour management. In particular, the relative scour depth $D_{R}$ is used as quantity to trigger actions.

The scour failure probability $P_{F}$ of a bridge is the probability that the normalised scour demand is greater than the normalised scour capacity of the bridge. The prior normalised scour demand $D_{P r}$ (Figure 5) can be expressed as a Normal distribution

$$
D_{P r} \sim \mathcal{N}\left(\bar{D}_{0}, \sigma_{D_{0}}\right)
$$

where $\bar{D}_{0}$ is the prior threshold of $D_{R}$ corresponding to a high risk of scour according to transport agencies, and $\sigma_{D 0}$ is the prior standard deviation of $D_{R}$ obtained with the BN.

Figure 5 Scour demand pdfs

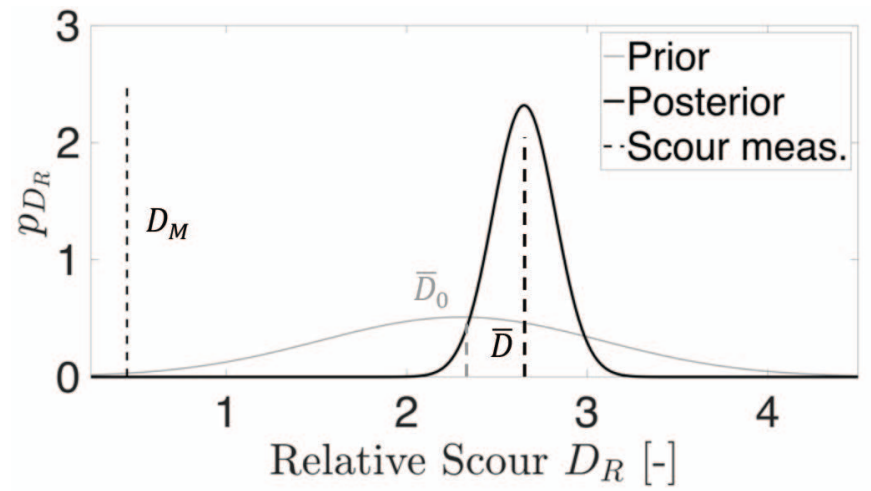

A fragility function $F_{C}$, consistent with the risk class given by BD97/12 (Figure 6), relates $D_{R}$ to the probability of failure $P_{F}$, 
and the unconditional prior probability of failure $P_{F, D O}$ can be written as:

$$
P_{F, D_{0}}=\int_{D_{R}} \mathcal{N}\left(\bar{D}_{0}, \sigma_{D_{0}}, D_{R}\right) F_{C}\left(D_{R}\right) d D_{R}
$$

Figure 6 Fragility function for the scour capacity $\mathrm{F}_{\mathrm{C}}$

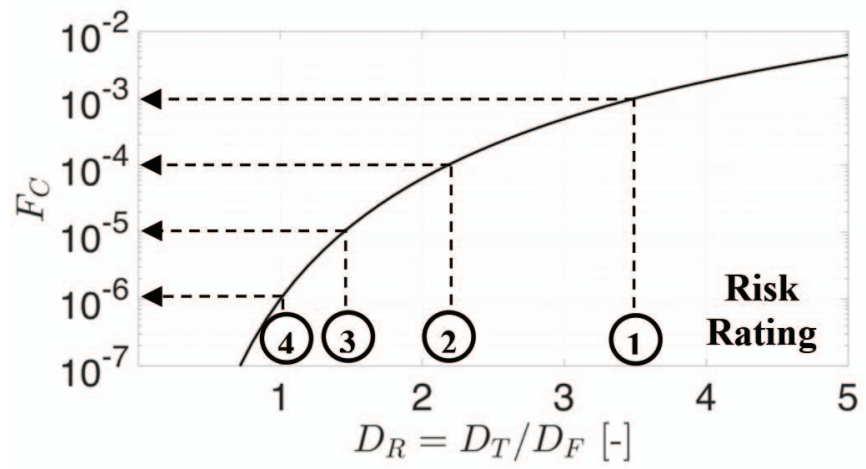

Equation (4) expresses the failure probability implicitly chosen by transport agencies when they fix their thresholds (i.e., the mean value of the prior scour demand $D_{P r}$ is the agency's threshold).

The BN provides an updating of the total scour depth distribution (i.e., posterior pdf in Figure 5). This BN's outcome can be used to express the posterior scour demand $D_{P}$ :

$$
D_{P} \sim \mathcal{N}\left(\bar{D}, \sigma_{\mathrm{P}}\right)
$$

where $\bar{D}$ is the posterior scour threshold and $\sigma_{P}$ is the posterior standard deviation updated by the BN. The probability of failure must remain equal to the one "a priori", depicted in Equation (4), to be consistent with the threshold defined by transport agencies. Thus:

$$
P_{F, \mathrm{D}}=\int_{D_{R}} \mathcal{N}\left(\bar{D}, \sigma_{\mathrm{D}}, D_{R}\right) F_{C}\left(D_{R}\right) d D_{R}=P_{F, \mathrm{D}_{0}}
$$

where $P_{F, D O}$ is expressed in Equation (4). The updated demand threshold corresponding to a high risk of scour is the value of $\bar{D}$ that satisfies Equation (6).

\section{Case study}

The functioning of the developed DSS is demonstrated using a small bridge network, consisting of bridges managed by Transport Scotland in south-west Scotland (Figure 7). The bridges cross the same river (River Nith), and only the first bridge is instrumented with a pilot scour monitoring system.

Figure 7 Small network of bridges over the River Nith. Red circles represent SEPA's gauging stations

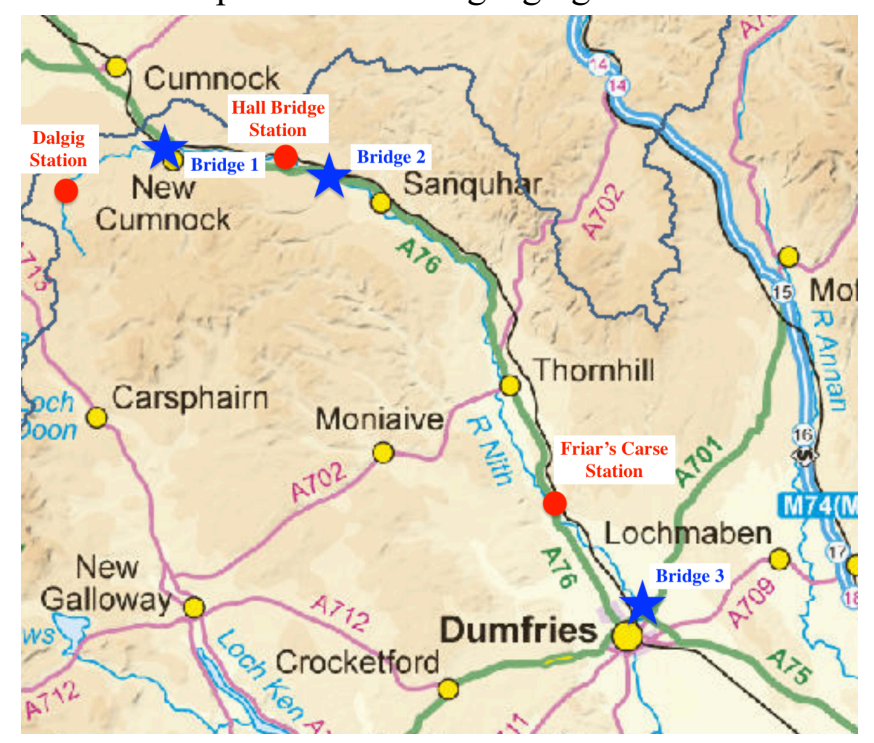

Three bridges with significant scour events in the past are chosen from the Transport Scotland scour database:

- Bridge 1: A76 200 bridge in New Cumnock shown in Figure $8(\mathrm{a})$. It is a 3-span stone-masonry arch bridge, with two piers in the riverbed. Abutments and piers are all founded on spread footings on the natural riverbed.

Figure 8 A76 200 bridge (a); A76 120 Guildhall bridge (b) and A75 300 Dalscone bridge (c)

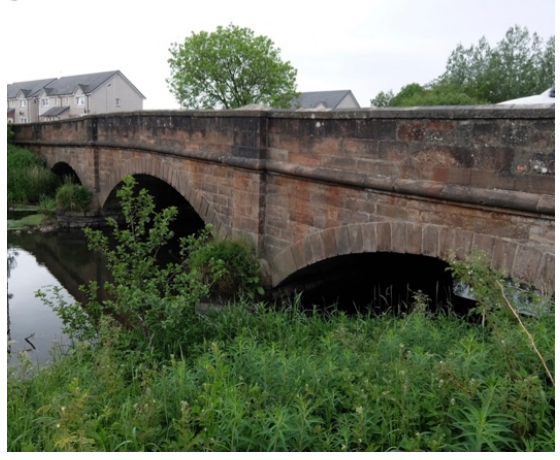

(a)

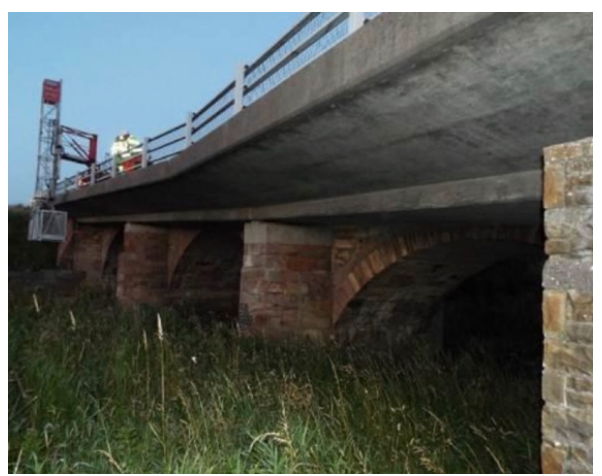

(b)

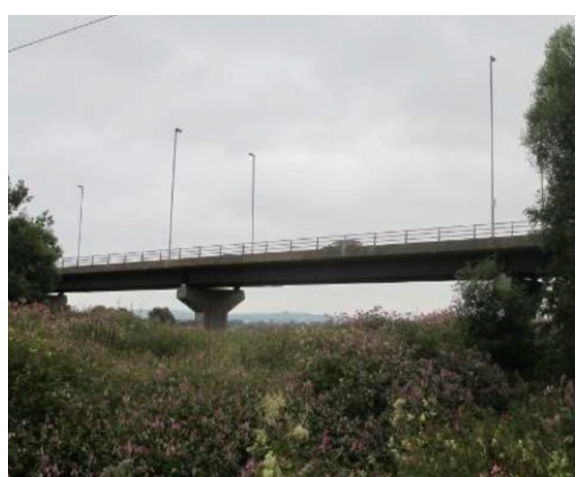

(c) 
- Bridge 2: A76 120 Guildhall bridge in Kirkconnel depicted in Figure 8(b). It is a 3-span masonry arch bridge, with one pier in the riverbed. Abutments and piers are all founded on spread footings on natural ground.

- Bridge 3: A75 300 Dalscone bridge in Dumfries shown in Figure 8(c). It is a 7-span steel-concrete composite bridge, with three piers in the riverbed. Abutments are founded on pile foundation on made up ground, while piers are all founded on pile foundation on natural ground.

The final BN for the estimation and updating of the total scour at every pier of the three bridges is depicted in Figure 9; each subnetwork related to each bridge is identifiable.

\section{Results}

Normal pdfs are employed for every variable except for river flows; a log-normal pdf was adopted because the discharge cannot be negative. The prior pdfs of the model uncertainties are set as Normal distributions defined by a zero mean and a coefficient of variation $(\mathrm{CoV})$. The parameters of the lognormal pdfs are obtained from the data recorded by SEPA's gauging station of the last ten years.

The predictive analysis is carried out by running a Monte Carlo method. 10.000 samples were extracted from every pdf in order to estimate "a priori" the total scour depth at the piers of the bridges. The outcomes are displayed in grey in the second column of Figure 10. The accuracy of the estimation at unmonitored piers is not satisfactory (i.e., $\sigma \approx 75 \mathrm{~cm}$ ).
The Transitional Markov Chain Monte Carlo (TMCMC) algorithm (Ching and Wang, 2016) is used to perform the Bayesian learning analysis and update the parent nodes. 1,000 samples were extracted at each stage of the TMCMC method, and the execution of the method is repeated 100 times for each updating (i.e., each application of TMCMC algorithm) in order to eliminate the influence of randomness.

Table 1 Case scenario for river level observations

\begin{tabular}{lll}
\hline SEPA station & Bridge & $\begin{array}{l}\text { Water level [m] } \\
30 / 12 / 2013\end{array}$ \\
& & \\
Dalgig & A76 200 & 1.879 \\
Hall Bridge & Guildhall & 3.015 \\
Friar's carse & Dalscone & 1.512 \\
\hline
\end{tabular}

The peak value of upstream river levels $y_{U}$ is chosen to simulate a heavy river flood condition (Table 1) and scour data are assumed to represent a critical situation: $20 \mathrm{~cm}$ for constriction scour depth $\mathrm{D}^{*} \mathrm{C}$ and $45 \mathrm{~cm}$ for total scour depth $\mathrm{D}_{\text {T }}$ at pier 1 of A76 200 bridge.

The algorithm estimates a mean value of $D_{T}$ on pier 2 that is equal to the scour measured at pier 1. It is the most probable result since the piers belong to the same bridge, their geometry is the same, the river bed material is the same, and the water flow is the same. However, it is an uncertain variable, with a standard deviation of $17 \mathrm{~cm}$. It is noteworthy that the standard deviation has reduced from $76 \mathrm{~cm}$ to $17 \mathrm{~cm}$, which is a decrease of around $80 \%$, due to the added information. The total scour $D_{T}$ at the unmonitored bridges can also be evaluated. A value of standard deviation close to $21 \mathrm{~cm}$ is obtained. This

Figure 9 BN developed for the case study

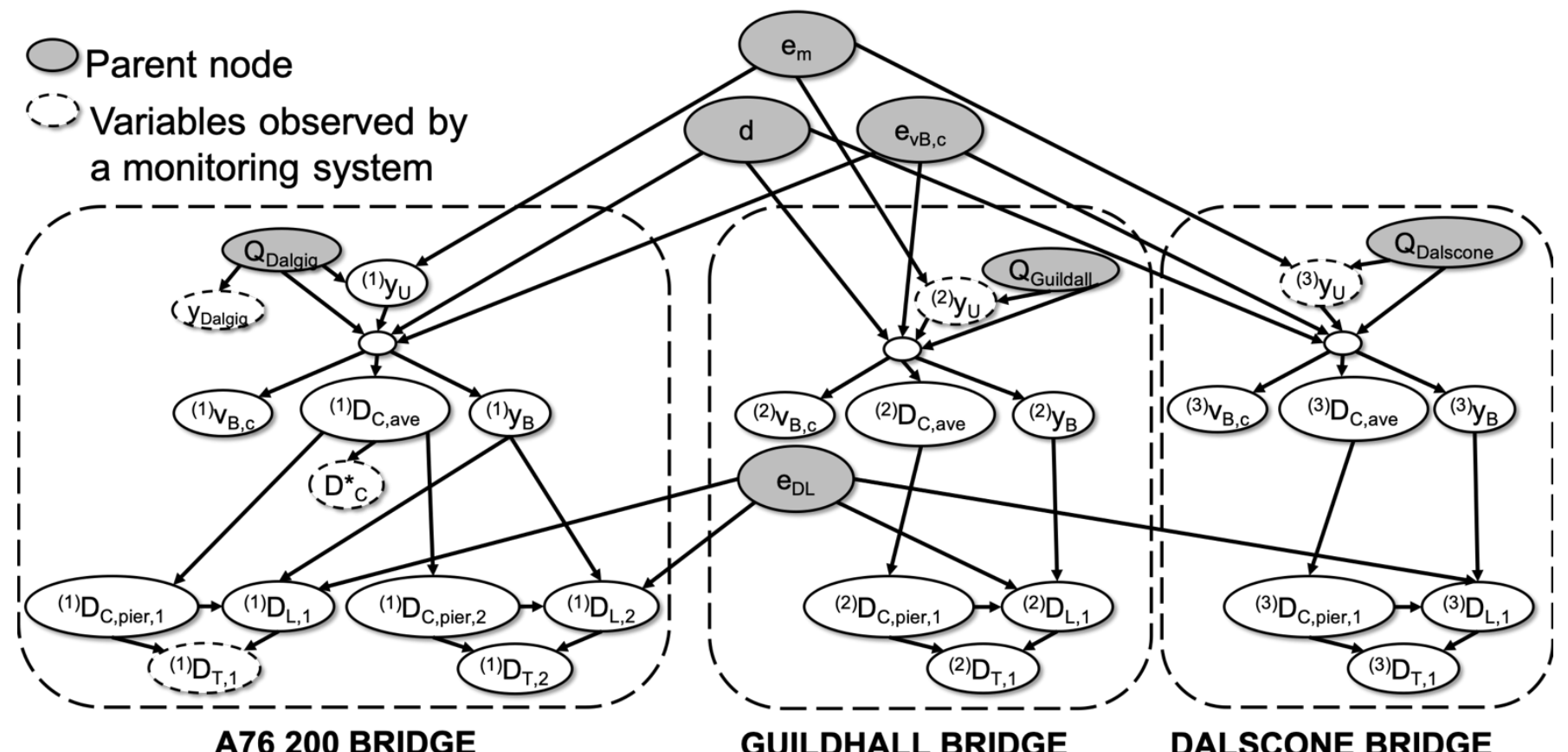


Figure 10 Updating of the scour threshold from BN's outcomes of unmonitored components

- A76 200 Bridge

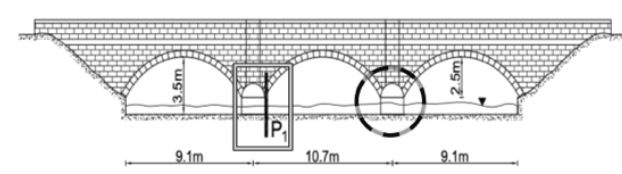

- Guildhall Bridge

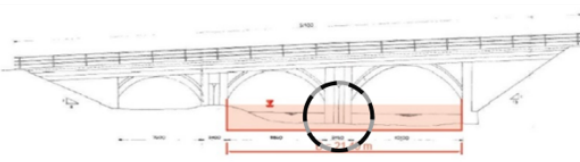

- Dalscone Bridge

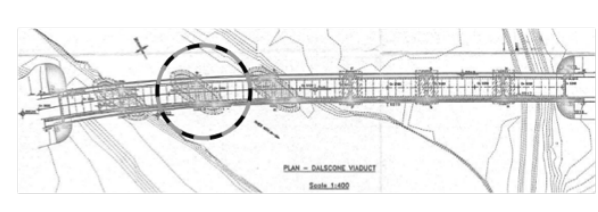

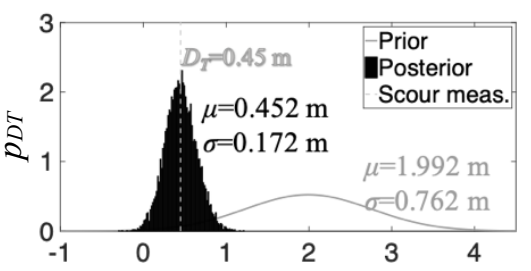
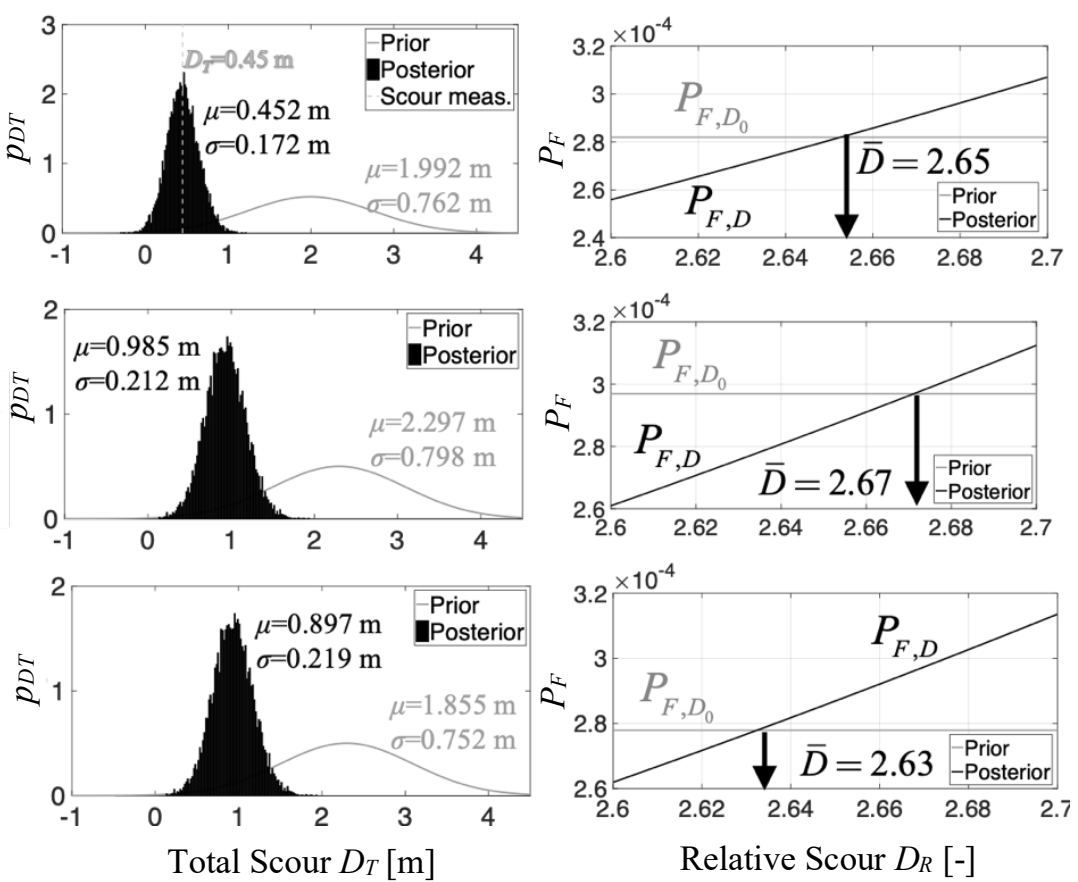

constitutes an increase (more than $70 \%$ ) in the accuracy compared to the prior results.

The third column of Figure 10 shows the outcomes of the scour threshold updating by exploiting the results obtained from the BN. The graphs depict the plotting of Equation (6) by varying the value of threshold $\bar{D}$. The failure probability $P_{F, D 0}$ (grey line) is a constant value because the threshold was chosen "a priori" by the agency. The intersection of the two straight lines provides the updated threshold that satisfies Equation (6). According to the scour risk classification performed by Transport Scotland (Figure 4(a)), the prior threshold $\bar{D}_{0}$ is chosen equal to 2.3 , i.e., the one that defines the boundary between risk class 3 and class 2 by assuming a priority factor equal to 2.0. Figure 10 shows that, starting from a prior threshold $\bar{D}_{0}=2.3$, the posterior estimation of the scour depth updated by the BN allowed increasing the scour threshold to a value of around $\bar{D}=2.66$.

\section{Conclusion}

In this paper, a prototype of a DSS for scour risk management for rail and road bridges is presented. It consists of a scour hazard model and a decision model. The former model is based on a $\mathrm{BN}$, which can update the scour depth using information from a scour monitoring system and river flow characteristics. The latter model can update the scour threshold after which the bridge is closed by exploiting BN's outcomes and observations collected by a scour monitoring system. Case study consisting of three bridges managed by Transport Scotland in South-West Scotland is used to demonstrate the functioning of the DSS.
The probabilistic framework shows that data from scour monitoring systems increase the accuracy on scour estimation compared to the prior results. This increase is in the order of $80 \%$ (from $76 \mathrm{~cm}$ to $17 \mathrm{~cm}$ ). Furthermore, the BN is also found to estimate accurately the scour depth at unmonitored, but correlated, bridges. In that case, the accuracy increases of more than $70 \%$, passing from a prior result of $76 \mathrm{~cm}$ to a value of standard deviation close to $21 \mathrm{~cm}$.

BN's outcomes and observations of the pilot scour monitoring system are used to update the scour threshold that triggers the bridge closure. The outcomes present an increase of the scour threshold that could help transport agencies in reducing the times that bridges might be closed unnecessarily as a precautionary action.

\section{Acknowledgements}

This work was carried out within the project "Early warning decision support system for the management of underwater scour risk for road and railway bridges" supported by the Natural Environment Research Council (NERC) under grant number NE/R009090/1.

\section{Reference}

Ben Gal I (2007) Bayesian Networks. In Encyclopedia of Statistics in Quality and Reliability (Ruggeri F et al. (eds)). Chester: Wiley.

Bensi MT et al. (2011) A Bayesian network methodology for infrastructure seismic risk assessment and decision support. University of California, Berkeley: Pacific Earthquake Engineering Research Center. 
Bolognani D et al. (2017) An application of Prospect Theory to a SHM-based decision problem. Portland, 2017. Proceedings of SPIE.

Briaud JL et al. (2007) Probability of scour depth exceedance owing to hydrologic uncertainty. Georisk, 1(2), pp.77-88.

Cappello C et al. (2016) Expected utility theory for monitoring-based decision making. Proceedings of the IEEE, 104(8), pp.1647-61.

Ching J and Wang JS (2016) Application of the transitional Markov chain Monte Carlo algorithm to probabilistic site characterization. Engineering Geology, 203, pp.151-67.

Department of Transport (2012) The assessment of scour and other hydraulic actions at highway structures (BD 97/12). UK: Design manual for roads and bridges.

Faber MH et al. (2002) Risk assessment of decommissioning options using Bayesian networks. Journal of Offshore Mechanics and Artic Engineering, 124, pp.231-38.

FEMA (2005). HAZUS MR4 technical manual: Flood model, Technical report, Washington D.C.: Federal Emergency Management Agency.

Friis-Hansen A (2000) Bayesian networks as a decision support tool in marine applications. PhD thesis. Denmark: DTU Department of Naval Architecture and Offshore Engineering.

HR Wallingford (1993) Hydraulic Aspects of Bridges Assessment of the Risk of Scour, Report EX2502. HR Wallingford.

Jensen FV and Nielsen TD (2007) Bayesian networks and decision graphs. 2nd ed. Berlin: Information Science and Statistics, Springer.

Kirby AM et al. (2015) Manual on scour at bridges and other hydraulic structures. London: CIRIA.

Korb KB and Nicholson AE (2010) Bayesian artificial intelligence. Boca Raton: Chapman and Hall/CRC.

Network Rail. (2016) Scotland route: extreme weather plan. Glasgow: Network Rail.

Porter KA (2003) An overview of PEER's performance-based earthquake engineering methodology. San Francisco, Proceedings of ICASP9.

Prendergast LJ and Gavin K (2014) A review of bridge scour monitoring techniques. Journal of Rock Mechanics and Geotechnical Engineering, 6, pp.138-49.

Rehg JM et al. (1999) Vision-based speaker detection using Bayesian networks. Proceedings of the IEEE Computer Society Conference on Computer Vision and Pattern Recognition.

Roca M and Whitehouse R (2012) Scour risk assessment at river crossings. Paris, 2012. Proceedings of ICSE 2012.

Straub D (2009) Stochastic modeling of deterioration processes through dynamic Bayesian networks. Journal of Engineering Mechanics, 135(10), pp.1089-99.

Transport Scotland (2018) Scour Management Strategy and Flood Emergency Plan. Glasgow: Transport Scotland.
Tubaldi E et al. (2017) A framework for probabilistic assessment of clear-water scour around bridge piers. Structural safety, 69, pp.11-22.

van Leeuwen Z and Lamb R (2014) Flood and scour related failure incidents at railway assets between 1846 and 2013. Railway Safety and Standards Board.

Wardhana K and Hadipriono FC (2003) Analysis of Recent Bridge Failures in the United States. Journal of performance of constructed facilities, 17(3), pp.144-50. 